\title{
Determining the causes of failure of the distillation column for the esterification of $n$-butanol with acetic acid
}

\author{
Stawomir Parzych ${ }^{1, *}$, Marek Gucwa ${ }^{2}$ \\ ${ }^{1}$ Cracow University of Technology, Institute of Materials Engineering, Faculty of Mechanical \\ Engineering, 37 Jana Pawla II St., 31-864 Cracow, Poland \\ ${ }^{2}$ Częstochowa University of Technology, Institute of Mechanical Technologies, Faculty of Mechanical \\ Engineering and Computer Science,69 J.H. Dąbrowskiego St., 42-201 Częstochowa, Poland
}

\begin{abstract}
The aim of the work is to determine the causes of corrosion of the distillation column from material 1.4571 (316Ti) in which acetic acid was produced. The column underwent a rapid and significant wear in a very short time during exploitation. To determine the causes of the failure, samples for testing were cut out of the components of the used distillation column. In the first test chemical analysis of the individual elements was carried out in order to specify the type of steel out of which they were made. The next step was to examine the structure of these elements and to perform microanalysis of the chemical composition of ferrite and austenite. After the completion and analysis of all necessary tests, conclusions were formulated to explain the causes of material consumption.
\end{abstract}

\section{Introduction}

Austenitic stainless steels are the most popular materials with anticorrosion properties. These steels normally have an austenitic matrix with a varying content of $\delta$ ferrite. The austenitic phase of stainless steels is stabilized down to room temperature by adding Ni into stainless steel matrix. The problem is that $\mathrm{Ni}$ being an expensive alloying element constitutes a major part of the total cost of austenitic stainless steels production, and the austenitic matrix is susceptible to the hot cracks. When the amount of $\delta$ ferrite is too low (below 5\%), hot cracks can occur during the welding process. An excessive amount of $\delta$ ferrite (above 10\%) causes a reduction in ductility, hardness and corrosion resistance in austenitic weldable stainless steels. The presence of $\delta$ ferrite in the structure of austenitic steel, heated during the welding or heat treatment, in the temperature range of $600 \div 900^{\circ} \mathrm{C}$, may cause the formation of an intermetallic compound of chromium and iron called the sigma $(\sigma)$ phase [1]. The sigma phase contains $40 \div 60 \%$ chromium, approx. $30 \%$ iron and slight amounts of nickel and molybdenum. This phase reduces ductility and impact resistance of weld metal and also impairs the corrosion resistance of stainless steels [2-4]. The major factors affecting the structure are Creq/Nieq ratio and heat input [5]. Depending on the current-voltage parameters, welding speed, and the welded element's thickness and

\footnotetext{
${ }^{*}$ Corresponding author: slawomir.parzych@mech.pk.edu.pl
} 
temperature, the rate of heat dissipation from the weld zone is varied [6]. The increase in heat dissipation rate for duplex steels causes the amount of $\delta$ ferrite in the structure to increase. In turn, in the case of austenitic and austenitic-ferritic steels, the fraction of ferrite in the structure grows up to a certain cooling rate and then it falls [7,8]. For the analysis of the amount of ferrite in stainless steels, Schaeffler diagrams and WWRC-1992 are normally used [9]. However, these diagrams consider, only the chemical composition of basic materials and fillers without taking into account the parameters of the welding process [10]. The aim of the work is to determine the causes of corrosion of the distillation column from material 1.4571 (316Ti) in which acetic acid was produced. 316Ti steel according to the literature [11] is completely resistant to highly concentrated acetic acid and temperature (Figure 1).

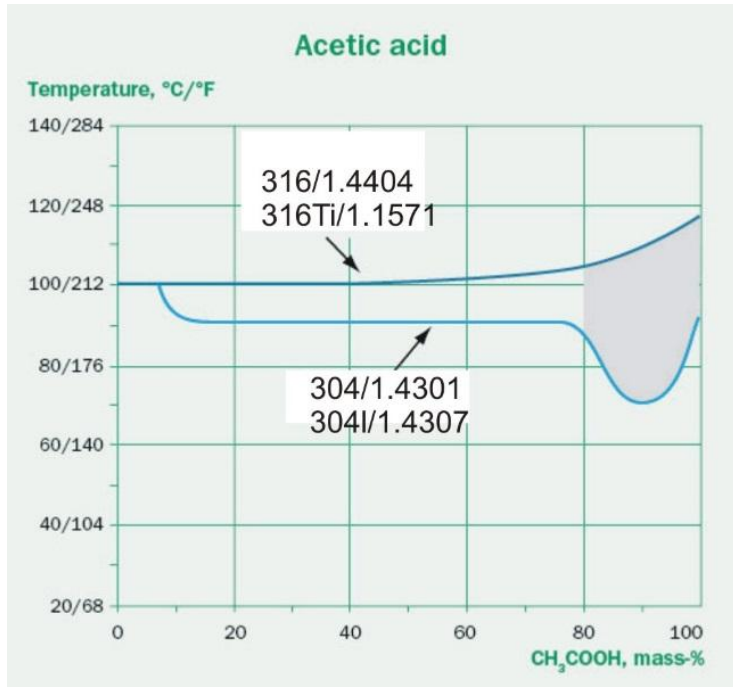

Fig. 1. Isocorrosion diagram, $0.1 \mathrm{~mm} /$ year, in acetic acid of chemical purity [11]

\subsection{Materials and methodology}

The material for the study was part of the distillation columns made of steel 1.4571 (316Ti), used for the esterification of n-butanol with acetic acid. The column after a short period of use was damaged in the form of a decrease in the wall thickness from $5 \mathrm{~mm}$ to about $1 \mathrm{~mm}$.

The scope of the research included:

- specify the type of material from which they were made delivered elements,

- determination of the structure of the material,

- determination of the cause of material wear.

The analysis of the chemical composition was performed using a Spectro-Lab spark spectrometer. Microstructure investigations were performed by means of light microscopy on an OLYMPUS GX51 optical microscope. The purpose of revealing the microstructure of the specimen was digested in royal water (a mixture of hydrochloric and nitric acid). When examining the microstructure scanning electron microscope Jeol model SM5510LV with EDS attachment was used.

\subsection{Results and discussion}

The column after a short period of use was damaged in the form of a decrease in the wall 
thickness from $5 \mathrm{~mm}$ to about $1 \mathrm{~mm}$. The cross-section of the column delivered for testing is presented in Figure 2. Chemical composition of steel 316 Ti according to the EN-10088 is presented in Table 1. The results of the analysis of the chemical composition of the section of the column obtained for testing are summarized in Table 2. The results of the analysis indicate that the chemical composition of the column section corresponds to AISI 316, AISI 316L and AISI 316Ti steel.

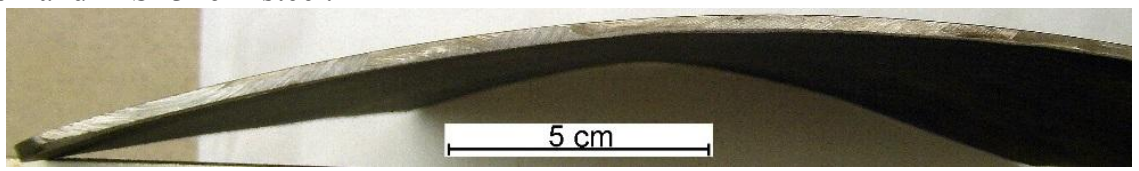

a)

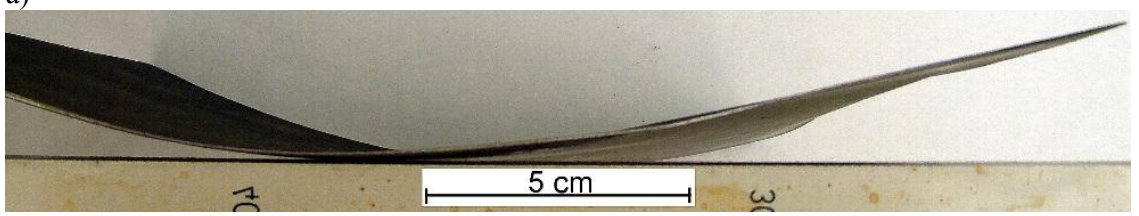

b)

Fig. 2. A cross-section of the part of the column delivered for testing: a) a section area about $4 \mathrm{~mm}$ thick, b) the area of the section about $1 \mathrm{~mm}$ thick.

Table 1. Chemical composition of steel $316 \mathrm{Ti}$ according to the EN-10088 [\% mass].

\begin{tabular}{|c|c|c|c|c|c|c|c|c|c|c|}
\hline $\mathbf{C}$ & $\mathbf{S i}$ & $\mathbf{M n}$ & $\mathbf{N i}$ & $\mathbf{C r}$ & $\mathbf{M o}$ & $\mathbf{T i}$ & $\mathbf{N}$ & $\mathbf{S m a x}$ & $\mathbf{P m a x}$ & $\mathbf{C u}$ \\
\hline$\leq 0.08$ & $\leq 1.00$ & $\leq 2.0$ & $\begin{array}{c}10.50- \\
13.50\end{array}$ & $\begin{array}{c}16.50- \\
18.50\end{array}$ & $\begin{array}{c}2.0- \\
2.50\end{array}$ & $\begin{array}{c}5 \mathrm{xC} \text { do } \\
0.70\end{array}$ & $\leq 0.11$ & 0.015 & 0.045 & $\leq 1.0$ \\
\hline
\end{tabular}

Table 2. Chemical compositions of tested samples [\% mass].

\begin{tabular}{|c|c|c|c|c|c|c|c|c|c|c|c|}
\hline & $\mathbf{C}$ & $\mathbf{S i}$ & $\mathbf{M n}$ & $\mathbf{N i}$ & $\mathbf{C r}$ & $\mathbf{M o}$ & $\mathbf{T i}$ & $\mathbf{N}$ & $\mathbf{S}$ & $\mathbf{P}$ & $\mathbf{C u}$ \\
\hline 1 & 0.0327 & 0.526 & 1.21 & 11.79 & 15.83 & 1.80 & 0.371 & 0.0395 & 0.00502 & 0.0328 & 0.278 \\
\hline 2 & 0.0283 & 0.536 & 1.19 & 11.21 & 16.02 & 1.86 & 0.373 & 0.0286 & 0.00422 & 0.033 & 0.257 \\
\hline 3 & 0.0421 & 0.431 & 1.32 & 11.36 & 16.25 & 1.91 & 0.446 & 0.0383 & $<0.001$ & 0.0329 & 0.425 \\
\hline 4 & 0.0514 & 0.667 & 1.58 & 11.26 & 16.14 & 1.92 & 0.321 & 0.0449 & 0.00134 & 0.034 & 0.393 \\
\hline
\end{tabular}

\subsection{Microstructures}

In each of the tested samples, an austenitic structure was found with delta ferrite bands, which may indicate the segregation of alloying elements in the examined components (Figure3). The distillation column study that was examined in the acetic acid environment was quickly consumed due to the incorrect structure of the steel used to make it. The presence of ferrite in the austenitic structure was the cause of excessive wear. Austenitic steel is a steel resistant to acetic acid, while ferritic steel is very corrosive. The chemical compositions presented in the attestations and the research carried out indicate a relatively low content of austenitic elements, which mainly include nickel. These values are, however, within the tolerance limits for this steel grade. A higher nickel content would give an austenitic structure without ferrite. The results of X-ray microanalysis revealed that the band structure is associated with a significant segregation of $\mathrm{Cr}, \mathrm{Ni}$ and $\mathrm{Mo}$ (i.e. elements strongly affecting corrosion resistance of stainless steels (Figure 4). 


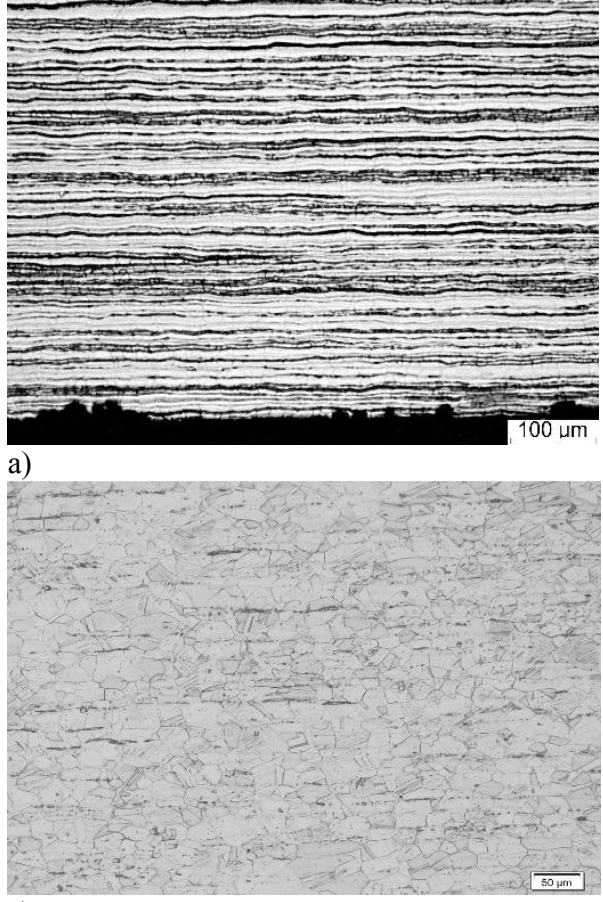

c)

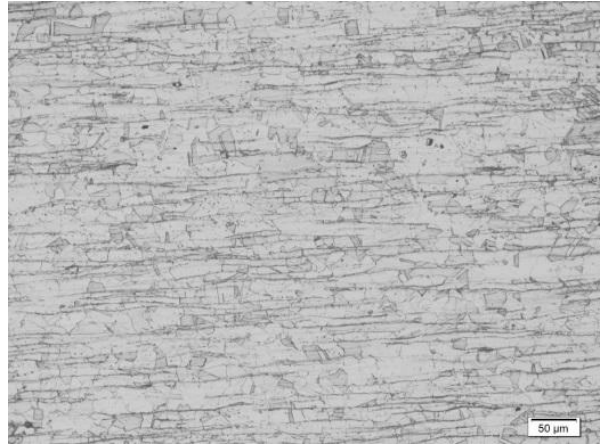

b)

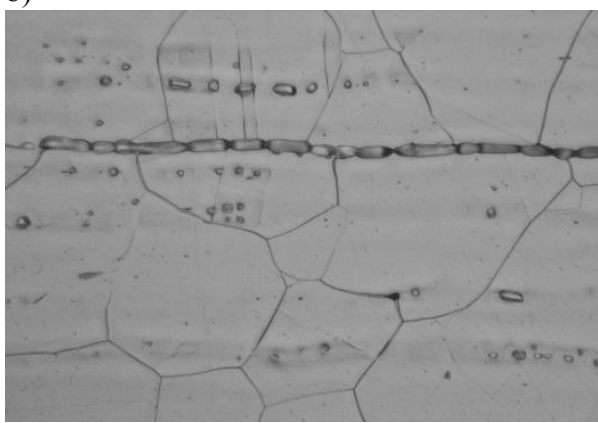

d)

Fig. 3. Austenitic microstructure with banded delta ferrite.
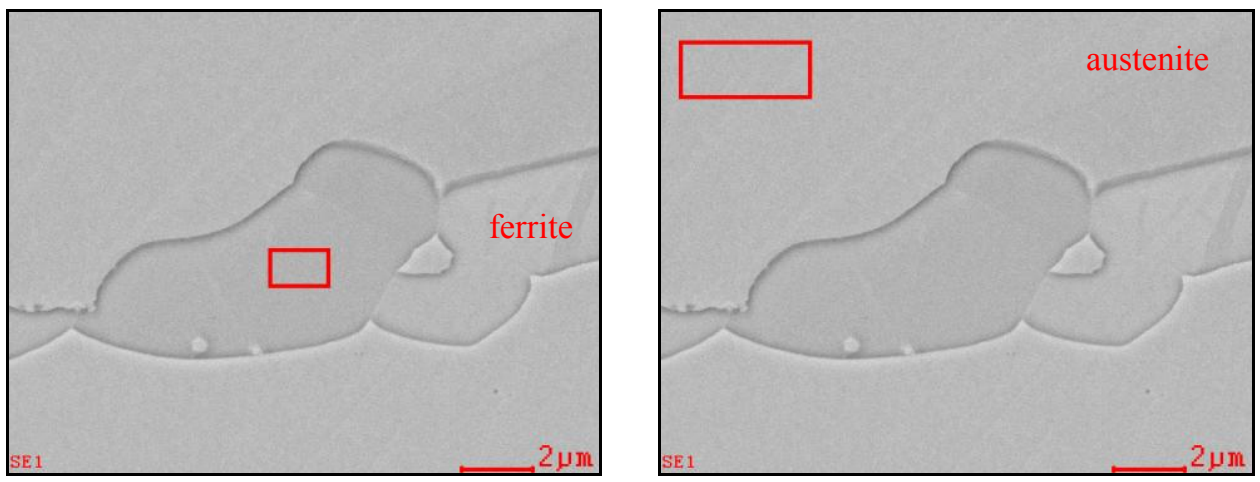

Fig. 4. Microanalysis of the chemical composition of ferrite and austenite.

Table 3. X-ray microanalysis column delivered for testing.

\begin{tabular}{|c|c|c|}
\hline \multirow{2}{*}{ Element } & Ferrite & Austenite \\
\cline { 2 - 3 } & \multicolumn{2}{|c|}{ content, \% } \\
\hline $\mathrm{Si}$ & 0.82 & 0.75 \\
\hline $\mathrm{Mo}$ & 4.47 & 1.97 \\
\hline $\mathrm{Ti}$ & 0.43 & 0.43 \\
\hline $\mathrm{Cr}$ & 22.23 & 14.46 \\
\hline $\mathrm{Mn}$ & 1.08 & 1.17 \\
\hline $\mathrm{Fe}$ & 65.50 & 67.81 \\
\hline $\mathrm{Ni}$ & 5.46 & 12.40 \\
\hline
\end{tabular}

A heat treatment was performed consisting of supersaturation from $1150^{\circ} \mathrm{C}$ in water. Samples were held at $1150^{\circ} \mathrm{C}$ for 30 minutes and then cooled in water. Appropriately high 
temperature causes the dissolution of the delta ferrite in the austenite and the high cooling rate prevents its re-isolation. The microstructure obtained is devoid of delta ferrite, only the austenitic microstructure is visible (Fig 5).

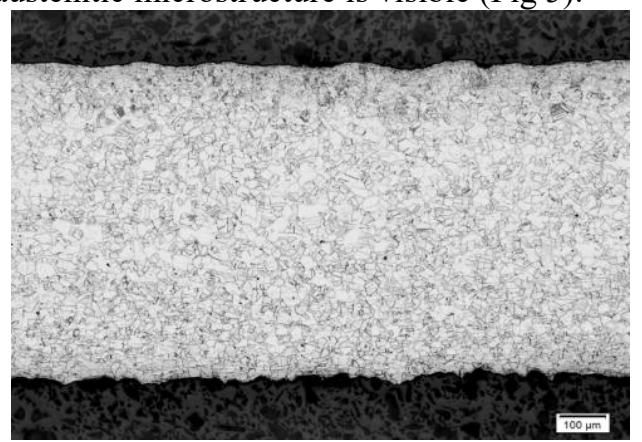

a)

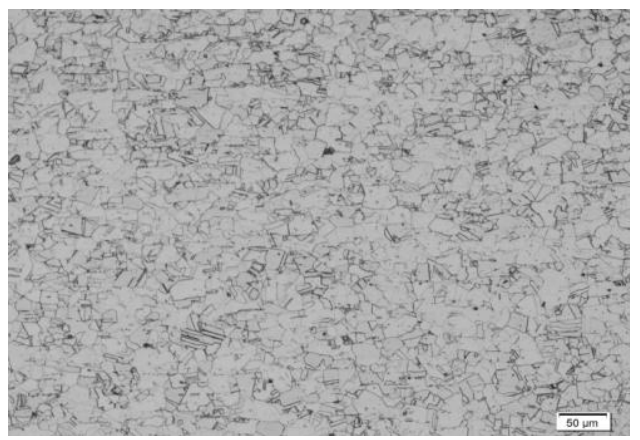

b)

Fig. 5. Austenitic microstructure without banded delta ferrite, microstructure of the sample after heat treatment.

\section{Summary}

Based on the results of performed study the following conclusions and recommendations relating to the manufacture and operation of the storage tanks butyl acetate, are drawn. The steel tested corresponds to the chemical composition of $316 \mathrm{Ti}$ steel in accordance with EN10088. Strong segregation of alloy components led to the appearance of banding in the structure which, with a limited content of austenitic components, led to the creation of a two-phase microstructure. The presence of delta ferrite in the structure adversely affects the corrosion resistance in an environment of butyl acetate. 316Ti steel may be used to make storage tanks for butyl acetate, subject to the need to test the presence of delta ferrite in the material structure. A heat treatment was carried out causing dissolution of the delta ferrite in the austenite. The obtained microstructure is devoid of delta ferrite, only the austenitic microstructure is visible.

\section{References}

1. A. Moteshakker, I. Danaee, J. Mat. Sci. Technol. 32 (2016)

2. A. Brodziak-Hyska, Z. Stradomski, C. Kolan, Arch. Foun. 14 (2014)

3. A.R. Khalifeh, A. Dehghan, E. Hajjari, Acta Metal. Sinica 26 (2013)

4. C.C. Hsieh, D.Y. Lin, M.C. Chen, W. Wu, Mat. Sci. Engin. A, 477 (2008)

5. M. Shojaati, B. Beidokhti, Constr. Build. Mat. 147 (2017)

6. J. Verma, R. V. Taiwade, J. Manuf. Proces. 24 (2016)

7. M. Vitek, S.A. David, C.R. Hinman, Welding J. 82 (2003)

8. R. Sudhakaran, V. VeL Murugan, P.S. Sivasakthivel, M Balaji, Int. J. Adv. Manuf. Techn. 64 (2013)

9. E. Tasak, Metalurgia spawania (JAK Publishers, Krakow 2008)

10. M. Gucwa, R. Bęczkowski, A. Grzyb, Arch. Foun. Engi. 14 (2014)

11. Outokumpu, Corrosion Handbook, Tenth Edition, 2009 